\title{
Future competencies for hospital management in developing countries: Systematic review
}

\author{
Zainab Malmoon ${ }^{1}$, Sogand Tourani*1(1), Mohammadreza Maleki ${ }^{1}$, Mehdi Jafari ${ }^{1}$ \\ Received: 20 May 2019 \\ Published: 3 Mar 2020
}

\section{Abstract}

Background: This was a systematic review presenting the future competencies for hospital managers.

Methods: Participants, interventions, comparisons and outcomes (PICO) strategy with MeSH terms were used for searching. Databases used were Web of Science, PsycINFO and Medline, EBSCO, ScienceDirect, Emerald, ProQuest, Social Sciences Research Network, Embase, and some Iranian database such as IRANDOC and SID. All publications were accepted if they had been published in English or Persian language and fulltexts were accessible. The study was carried out using a systematic literature search published between January 1995 and December 2018. The Endnote v.17 software was used to facilitate reference management. Quality assessment of publications were carried out independently by two reviewers using the Critical Appraisal Skills Programme (CASP) and the Preferred Reporting Items for Systematic Reviews and Meta-Analyses (PRISMA) checklist. A descriptive summary with data tables produced to summarize the literature. Data extraction was conducted by two researchers.

Results: Forty seven studies were analyzed to identify the future competencies required for hospital managers. In all, 3190 publications were retrieved. 1934 citations were excluded because of irrelevant $(n=2600)$, duplicates $(n=316)$, and unavailable full text $(n=18)$. After studying the 256 remaining publications, 33 citations were extracted and presented. After extracting the future competencies of hospital managers, competencies were classified into four main categories based on the qualitative meta-synthesis process.

Conclusion: The most important competencies in the future are global knowledge, Key Eligibility Criteria, wide attitude and core skills that must be addressed in the face of ambiguity.

Keywords: Competency, Hospital manager, Future

Conflicts of Interest: None declared

Funding: The project is supported by the Iran University of Medical Sciences by the contract number IUMS/SHMIS_1396/9321532004.

\section{*This work has been published under CC BY-NC-SA 1.0 license.}

Copyright $\odot$ Iran University of Medical Sciences

Cite this article as: Malmoon Z, Tourani S, Maleki M, Jafari M. Future competencies for hospital management in developing countries: Systematic review. Med J Islam Repub Iran. 2020 (3 Mar);34:15. https://doi.org/10.47176/mjiri.34.15

\section{Introduction}

In today's developing world, successful organizations try to use management and organizational transitions in order to survive and continue their activities and to enter into the global competition (1). Acceptance of this transformation requires some tools. One of them is the use of appropriate methods to attract talents and training future managers with the competency-based selection and competency-planning approach. Due to the transition to the meritocracy system, this is more dramatic in all organizations, especially those

Corresponding author:Dr Sogand Tourani, tourani.s@iums.ac.ir

1. Department of Health Services Management, School of Health Management and Information Sciences, Iran University of Medical Sciences, Tehran, Iran that rely more on knowledge forces (2). The concept of competency is one of the approaches that has been released into the world of management in recent decades. This approach was proposed by McClelland in 1970 (3). Competency is a set of knowledge, skills and attitudes that enable employees to work effectively on the job or job performance according to standard. Competency is an improbable behavior that is required for success. Managerial competency is a set of behaviors and attitudes that is necessary for

$\uparrow$ What is "already known" in this topic:

Competencies of hospital managers are key issues for increasing productivity in hospitals. Given the changing role of hospitals in the community, it is necessary to identify and categorize the main competencies.

$\rightarrow$ What this article adds:

This article, by reviewing the evidence of studies, identifies and presents the future competencies of hospital managers. 
effective managerial activities in every organization $(4,5)$.

Because of challenges ahead, a forward-looking organization needs more capable and more competent managers. Since the hiring and employment of managers are costly, we must prevent the appointment of incompetent managers and damage caused by it. Full implementation of meritocracy needs some steps such as competency-seeking, competency-recognizing, competency- planning, competencybased selection and meritocracy (6).

According to the Global Competitiveness Report, managerial skills have 8 features, including technical skill, management experience in human resources topics, communication and competitiveness, leadership, entrepreneurship responsibility, flexibility, culture and providence (7).

Studies show that managers with proprietary metrics such as dependencies, family relationships, advice, ethnicity etc. prevent the proper performance and development of the organization. In the other hand, selecting based on public metrics and meritocracy like a commitment, experience, expertise, etc. improve the performance of the organization (8). Since the existence of the meritocracy system in each country will cause consistency, acceptability and legitimacy, therefore selecting competent managers is very important for every organization, especially hospitals which play a vital role in society. Creative and innovative organizations are key elements for countries. This is very important to health care organizations that are responsible for maintaining, supplying, maintenance, health promotion, and control and prevention of diseases because management is a major component of healthcare organizations. Due to the dynamic, alive and changeable nature of this section, mangers have to coordinate with the changes and developments (9).

Studies show that lack of proper management and management capability in health care organization lead to not achieved goals in the health sector. Therefore, all efforts to improve the implementation of policies in the health sector have not delivered or have been followed slowly (10). Another study revealed that we should use adaptable and flexible managers and effective leaders to deal with the current challenges in the health care sector. As a result, using effective managers in this phase will prevent the waste of resources and increase productivity (11).

In theory and practice, management of health care organizations is a very difficult task. This is very important because there are various personnel, facilities, and expensive equipment. Due to globalization and superior technology, competition in the health area is dependent on health care policy. The effectiveness of health care organizations is directly linked with the quality of decisions of managers in this section. Recent studies showed that managers have a significant role in promoting health systems. The scientific community in the field of health should seek to define and identify the competencies needed for managers, especially hospital managers (12).

Despite the unique facilities, hospital, as one of the existing organizations, play a significant role in the treatment of mental and physical problem, training the specialist, health research and finally improving the health. Team-based or- ganizations such as the health care section that have complex, dynamic and vulnerable environments, need the managers who have the ability to shape the competency of team members(13). Because a hospital is a social organization and is one of the important units for providing health services, the poor performance of managers leads to delayed treatment and disease progression or even death. When there are incompetent managers in hospitals, resources could be wasted and ultimately productivity will be reduced (14).

Health managers must identify the gaps in management skills. Defining and assessing these skills are very important and play a significant role in the continuous improvement of health services. Identifying and publishing these competencies is very helpful and we need to design a proper educational program for better performance of managers. Many countries have faced many changes in the field of health care services as well as customer demand. Therefore, without a formal program for identifying skills and training managers, many of them will be faced with problems in developing the necessary knowledge and skills to identify the issues such as the efficiency of services, quality of care and meet the expectations of patients $(15,16)$.

The competencies required for management in a highly complex organization, such as a hospital, are critical. In many countries, including Iran, due diligence has not been not given to suitability issues. This study seeks to highlight the competencies needed by hospital managers and strives to provide competencies for future development as a basis for decision making.

The future is an enormous ambiguity and complexity, and health professions will face increasing complexity. In order to understand how managers should behave in future organizations, they should have a proper understanding of their competencies in the future. In this study, we used a systematic review to determine the future competencies of hospital managers.

\section{Methods}

This review protocol followed the Cochrane Database of Systematic Reviews (CDSR) (17). A protocol outlines the question that the review authors are addressing, detailing the criteria against which studies will be assessed for inclusion in the review, and describing how the authors will manage the review process. The CDSR protocols contain the four review process, including identification of relevant studies, selection of studies for inclusion and evaluation, systematic collection of data, and appropriate synthesis of data. For enhancing the quality and transparency of research, we used the Preferred Reporting Items for Systematic Reviews and Meta-Analyses (The PRISMA Statement).

\section{Inclusion Criteria}

Studies were included if they were published in English or Persian in peer-reviewed scientific journals. The participants, interventions, comparisons, and outcomes (PICO) strategy along with the following keywords obtained from PubMed (MeSH terms) were used for searching. All foreign studies, between 1995 and 2018 and Persian studies 
that have been published between 2005-2018 were included. The research was done in December 2019.

\section{Types of Participants}

Studies were included if participants were hospital managers or health proficient.

\section{Types of Interventions}

Competency is the capability to apply or use the set of related knowledge, skills, and abilities (KSA) required to work successfully. We selected the resources that mentioned KSA on hospital managers.

\section{Types of Outcome Measures}

Studies that included the mentioned competencies.

\section{Types of Studies}

All types of study designs were included.

\section{Exclusion Criteria}

Articles with insufficient details or inaccurate with hospital management were ineligible.

\section{Data Sources and Search Strategy}

The search strategy is based on the search of a phrase and by combining Boolean functions. Google scholar was first used for finding resources and identifying keywords and other synonym expressions, then obtained words were used alone or along with "OR" and "AND", as well as the Truncation Technique. The strategy included a combination of Medical Subject Headings terms and keywords related to the population (hospital manager), intervention (e.g., key competencies, Competence, Competency-Based Education, meritocracy), comparison condition (e.g., future, futurology, Forecasting, trends)

The following 12 electronic databases were searched from inception to November 2015: Web of Science, PsycINFO and Medline, EBSCO, ScienceDirect, Emerald, ProQuest Journals, Social Sciences Research Network, ERIC, PubMed, Embase, Journal, SID and Irandoc.

\section{Study selection}

All types of publications such as reviews, systematic reviews and meta-analysis, qualitative, quantitative, books, reports were accepted if they had been published in English or Persian language, and their full text were accessible. The titles of the retrieved citations checked independently by two reviewers according to the above selection criteria. Full text copies of potentially relevant studies obtained and their appropriateness for inclusion were independently assessed by two reviewers. Literatures that do not fulfill all of the inclusion criteria were excluded. The Endnote v.17 software was used to facilitate reference management.

Quality assessments of publications independently were carried out on each study by two reviewers using the relevant version of the Critical Appraisal Skills Programme (CASP) for qualitative research. Similarly, the Preferred Reporting Items for Systematic Reviews and Meta-Analyses (PRISMA) checklist used for assessing systematic reviews.

\section{Data collection}

A Preferred Reporting Items for Systematic Review and Meta-Analysis flow diagram was prepared to show the overall process of study selection and the number of citations reviewed at each stage of this review.

\section{Results}

\section{Data synthesis and reporting}

The PRISMA checklist was used to guide the reporting of the systematic review. A descriptive summary with data tables produced to summarize the literature. Details related to the study's target were extracted and items such as findings of the study, the time of publication, the environment, sample, sampling, statistical analysis, data collection methods, results and discussion of each study were considered. Data extraction was conducted by two researchers. According to the aim of the study and after quality appraisals, 47 studies were analyzed to identify the competencies required for hospital managers (Table 1).

Table 1. Summary of Studies and Stratification by Geographic Region

\begin{tabular}{|c|c|c|c|}
\hline Title & Lead Author & Year & Country \\
\hline $\begin{array}{l}\text { Factors Affecting The Future Studies Of Educational Hospitals Of Kerman University Of Medical } \\
\text { Sciences (18) }\end{array}$ & Ghorbani Nia, R. & 2018 & Iran \\
\hline Developing Competence Modeling Of Hospital Managers (19) & Kermani, B. & 2017 & Iran \\
\hline $\begin{array}{l}\text { A Leadership And Managerial Competency Framework For Public Hospital Managers In Vietnam } \\
(20)\end{array}$ & Van Tuong, $\mathrm{P}$. & 2017 & Vietnam \\
\hline Analyzing Competencies Of Health Care Leaders: Way Forward For Next Generation (21) & Patnaik, SK. & 2017 & India \\
\hline A Qualitative Study To Identify Skills And Competency Required For Hospital Managers (22) & Barati, O. & 2016 & Iran \\
\hline Leadership Competencies For Healthcare Services Managers (23) & $\begin{array}{c}\text { The International } \\
\text { Hospital } \\
\text { Federation }\end{array}$ & 2015 & Swiss \\
\hline Leadership In Public Health: New Competencies For The Future (24) & Yphantides, N. & 2015 & USA \\
\hline Redefining The Core Competencies Of Future Health Care Executives Under Healthcare Reform (25) & Love, Dianne, B. & 2015 & USA \\
\hline $\begin{array}{l}\text { Future Health Care Managers And The Need For An International And Interprofessional Learning } \\
\text { Experience :The Case Of A Summer School On Cross-Border Health Care (26) }\end{array}$ & Sinz, H. & 2015 & Austria \\
\hline The Study Of Various Models Of Hospital Manager's Competency (27) & Hayati, H. & 2015 & Iran \\
\hline $\begin{array}{l}\text { Managerial Competencies-A Survey Of Hospital Managers' Working In Kathmandu Valley, Nepal } \\
\text { (28) }\end{array}$ & Khadka, DK. & 2014 & Nepal \\
\hline $\begin{array}{l}\text { Developing Leadership And Management Competencies In Low And Middle-Income Country Health } \\
\text { Systems: A Review Of The Literature (29) }\end{array}$ & Daire, J. & 2014 & $\begin{array}{l}\text { South } \\
\text { Africa }\end{array}$ \\
\hline
\end{tabular}




\begin{tabular}{|c|c|c|c|}
\hline Title & Lead Author & Year & Country \\
\hline $\begin{array}{l}\text { Cultural Competency Of Health-Care Providers In A Swiss University Hospital: Self-Assessed } \\
\text { Cross-Cultural Skillfulness In A Cross-Sectional Study (30) }\end{array}$ & Casilas, A. & 2014 & Swiss \\
\hline $\begin{array}{l}\text { Measuring Competency Model For Managers In The Health Sector (Structural Equation Mod- } \\
\text { eling Approach) (31) }\end{array}$ & Ranjbar, M. & 2014 & Iran \\
\hline Review Of Hospital Manager's Competencies In Astana (32) & Umbetzhanova, A. & 2014 & Kazakhstan \\
\hline $\begin{array}{l}\text { Assessment Of Effective Management Skills In Managers Of Teaching Hospitals In Qazvin } \\
\text { University Of Medical Sciences (33) }\end{array}$ & Kiaei, MZ. & 2014 & Iran \\
\hline $\begin{array}{l}\text { Managers' Development Needs Assessment: Perspective Of Middle Managers Of Public Hos- } \\
\text { pitals Of Tehran (34) }\end{array}$ & Farzianpour, F. & 2013 & Iran \\
\hline $\begin{array}{l}\text { Victorian Junior Doctors' Perception Of Their Competency And Training Needs In Healthcare } \\
\text { Management (35) }\end{array}$ & Schoenmaker, SG. & 2013 & Netherland \\
\hline $\begin{array}{l}\text { Scenario-Specific, Statistically Sound, Problem-Driven Approach To Data Analysis - A Ro- } \\
\text { bust Tool For Future Health Managers (36) }\end{array}$ & Rinkoo, AV. & 2013 & India \\
\hline $\begin{array}{l}\text { Evaluation Of Managers Based On } 360 \text { Degree Feedback In Teaching Hospitals Of Tehran } \\
\text { University Of Medical Sciences (37) }\end{array}$ & Yousefinezhadi, T. & 2013 & Iran \\
\hline $\begin{array}{l}\text { Critical Managerial Activity And Competency Of Healthcare Management: A Study Of Eight- } \\
\text { een Hospitals (38) }\end{array}$ & Lin, LM. & 2012 & Taiwan \\
\hline $\begin{array}{l}\text { Identification Of Key Capabilities For Effective Implementation Of Knowledge Management } \\
\text { In Hospitals With Structural Equation Modelling Approach Health Management (39) }\end{array}$ & Ehsani, A. & 2012 & Iran \\
\hline $\begin{array}{l}\text { Management Of The Free Health Care Initiative In Sierra Leone: Does The Health Workforce } \\
\text { Have The Right Managerial Competencies? (40) }\end{array}$ & Ganda, G. & 2011 & Sierra Leone \\
\hline $\begin{array}{l}\text { The Relationship Between Managerial Competencies And Hospital Efficiency At Tehran Uni- } \\
\text { versity Of Medical Sciences (41) }\end{array}$ & Tabibi,SJ. & 2010 & Iran \\
\hline $\begin{array}{l}\text { Hospital Management Training And Improvement In Managerial Skills: Serbian Experience } \\
\text { (42) }\end{array}$ & Supic, Z T. & 2010 & Serbia \\
\hline $\begin{array}{l}\text { The Skills Gap In Hospital Management: A Comparative Analysis Of Hospital Managers In } \\
\text { The Public And Private Sectors In South Africa (43) }\end{array}$ & Pillay, R. & 2010 & South Africa \\
\hline $\begin{array}{l}\text { Competency Development Among Taiwanese Healthcare Middle Manager: A Test Of The } \\
\text { AHP Approach (44) }\end{array}$ & Fang, $\mathrm{CH}$. & 2010 & Taiwan \\
\hline Educating Leaders In Hospital Management: A New Model In Sub-Saharan Africa (45) & Kebede, S. & 2009 & $\begin{array}{l}\text { Sub-Saharan } \\
\text { Africa }\end{array}$ \\
\hline Health Care Management Competencies: Identifying The Gaps (46) & Lockhart, W. & 2009 & France \\
\hline Assessment Of Human Resources Management Practices In Lebanese Hospitals (47) & El-Jardali, F. & 2009 & Lebanon \\
\hline $\begin{array}{l}\text { Common Competencies For All Healthcare Managers: The Healthcare Leadership Alliance } \\
\text { Model (48) }\end{array}$ & Stefl, M. & 2008 & USA \\
\hline $\begin{array}{l}\text { Physician perceptions of managed care strategies, and impact of these on their clinical perfor- } \\
\text { mance, in the South African private health sector (49) }\end{array}$ & Pillay, R. & 2008 & South Africa \\
\hline $\begin{array}{l}\text { Defining Competencies For Hospital Management: A comparative analysis of the public and } \\
\text { private sectors (50) }\end{array}$ & Pillay, R. & 2008 & South Africa \\
\hline
\end{tabular}

In all, 3190 publications were retrieved. 1934 citations were excluded because of irrelevant $(n=2600)$, duplicates $(n=316)$, and unavailability of full texts $(n=18)$. After studying the 256 remaining publications, 33 citations were extracted and presented (Fig. 1).
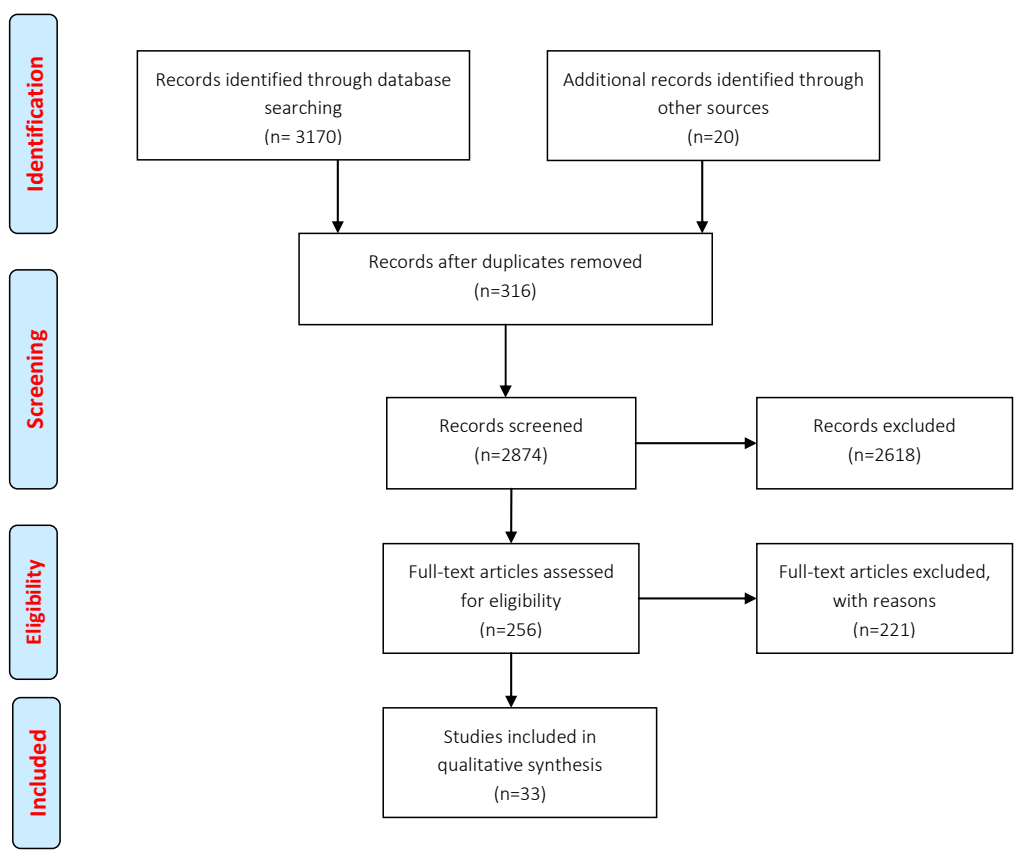

Fig. 1. PRISMA Flow Diagram

$4 \quad$ http://mjiri.iums.ac.ir

Med J Islam Repub Iran. 2020 (3 Mar); 34:15. 


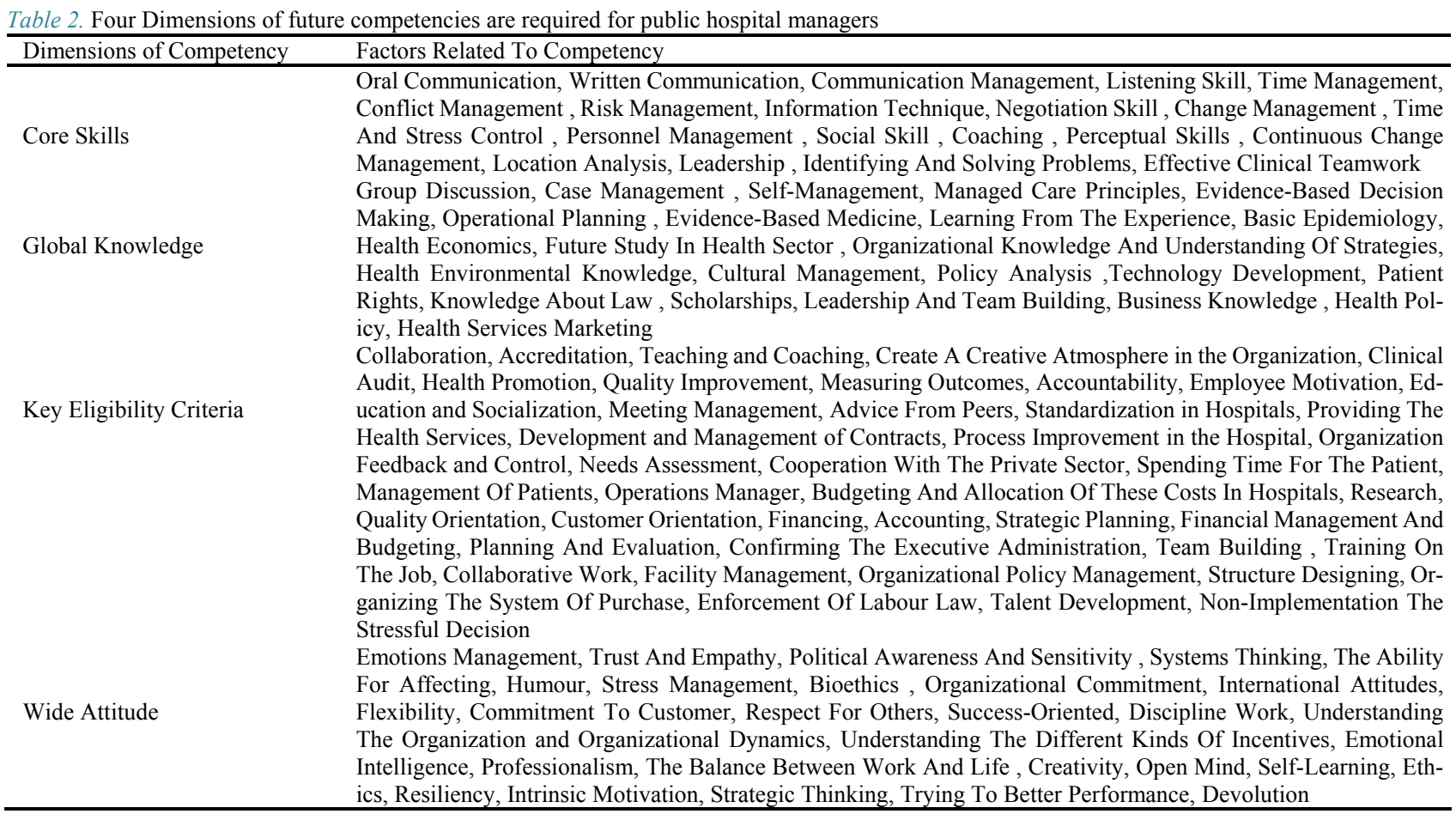

After extracting the future competencies required by hospital managers, competencies were classified into four main axes based on the qualitative meta-synthesis process (Table 2).

\section{Discussion}

Studies have shown that hospital managers need to have different competencies for the sake of a complex organization. Some studies have referred to public competence, and others are of technical merit. The important thing was that the future merits of hospital managers are different from the past. Hospital managers have four duties: planning, organizing, directing and control. Because they are dealing with human lives, maximum organizational complexity arises. They should have competencies to perform their duties effectively. There should be a list of management competencies to plan and evaluate the performance of hospital management; until we can provide organizational growth by relying on the principle of meritocracy (51). For theoretical coherence and organizing competencies, extracted cased in this systematic review were classified into four groups (core skill, global knowledge, key eligibility criteria and wide attitude) based on competency (Fig. 2).

Core Skill means the ability to transform knowledge into practice. Skill obtained and improved by repeated performance of knowledge in the real environment. Improving the skill leads to the improvement in the quality of performance. Knowledge without action is not effective. In the future, managers will need different skills, and their lack of performance will greatly affect their performance. Hospital managers should have core skills in the future for greater effectiveness (52). The 20 major skills were recognized in our review to promote managerial competencies in hospital. The most important of them were information and communication skills, leadership and solving-problem in hospitals, human skills, negotiation and conflict management.

The theoretical knowledge is obtained through education at the university level. Development of knowledge is the cornerstone of skills and attitude and does not have much influence on the development of managerial competencies by itself $(53,54)$. With reviewing the studies on the future competency of hospital managers, 23 knowledge were

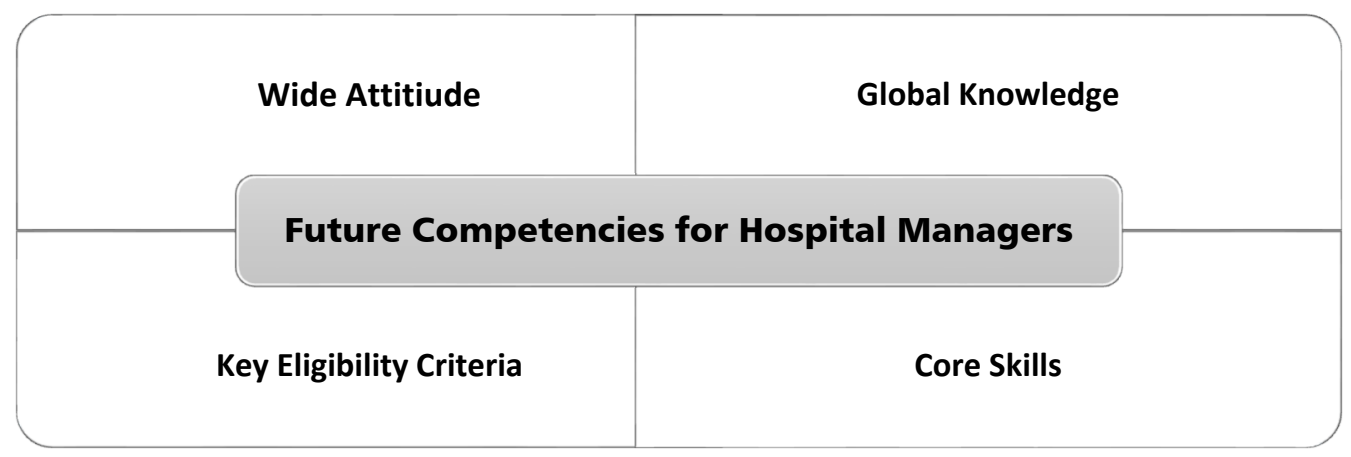

Fig. 2. Four Dimensions of Future Competencies for Public Hospital Managers 
identified which we called it global Knowledge. The most important items were self-management, evidence-based knowledge of decision-maker, marketing and health economics. Future changes are global changes, and the manager must have knowledge of work in this global village.

Key eligibility criteria have a stable and broad nature that helps people to perform the physical and mental jobs in the best way possible. In fact, skill and eligibility are the same. Their difference is that the skill is a specific capacity for doing the physical things, but the eligibility is to specify the capacity for doing intellectual work $(55,56)$. Results showed that 44 Key eligibility criteria could increase competency in hospital managers and the effectiveness of management activities in hospitals in the future. The following items can also be mentioned: creating the hospital strategies in uncertainly, allocation of the cost of a hospital to multiple needs of units and the development of appropriate organizational policies to improve processes in hospitals.

Wide attitude is the mental image of humans about the world and environment. The mental image is a framework that shapes the thought and action. The world of the future is the world of continuous change and singularity in technology (57). We recognized 29 features as the attitudes that will improve the health professions' competencies. The most important identified attitudes were included: strategic attitude, ethical principles in hospital, patient-centeredness and work discipline.

However, managers are under pressure to overcome the challenges of effective service delivery in hospitals, but very little formal evaluation has been conducted about health professions' capacities and needs for future training $(58,59)$. Future organizations are different from organizations with different roles in society. The growth of technology and epidemiological changes, along with changes in governance and economic paradigms, greatly affect the structure of the hospital (60). Hospital managers know that they will not be able to manage future hospitals with current competency. Having a wide and holistic attitude, key skills, knowledge on a global scale and key competencies will increase their effectiveness.

\section{Conclusion}

It is essential to explain the future competencies of hospital managers to improve the efficiency and responsiveness to the changing role of hospitals. In addition to the core competencies that are necessary for management in the present and future, having a broad attitude towards global environmental and knowledge changes and management in the field of information and communication technology will be the most important competencies of a hospital administrator in the future.

\section{Acknowledgments}

This study was part of a phd thesis in health administration supported by Iran University of Medical Sciences (IUMS). the project is supported by the IUMS by the contract number iums/shmis_1396/9321532004. a code of ethics committee is iums.rec 1396.9321532004.
Conflict of Interests

The authors declare that they have no competing interests.

\section{References}

1. Tank IaTt. the digital health. Tehran, Iran: Secretariat of the National Forecasting Program in the field of Health Foresight, 2018.

2. Ogbonnia Godfry O, Chikezie N. managerial competency among hospital managers: does experience on the job matters. J Soc Sci Manag Res. 2018;4(3):88-103.

3. Shaw J. Hospital managers of the future--what are their needs World Hosp Health Serv. 2000;36(2):11-4, 44-5.

4. Calhoun JG, Davidson PL, Siniors ME, Vincent E T, Griffith JR. Toward an Understnding of competency Identification and Assessement in Health Care Management. Qual Manag Health Care. 2002;11(1).

5. Oshins M. Identifying a Competency Model for Hotel Managers. New York: State University of New York at BinghamtonS; 2002.

6. Sherman R, Dobbins D, Tibbetts J, Crocker J, Dlott M. Management Competencies Assessment Instrument. A Publication of Building Professional Development Partnerships for Adult Educators Project. PRO-NET 2000. 2002.

7. Mulder M. A five-component future competence (5CFC) model. Taylor \& Francis; 2017.

8. Mosaddegh Rad AM, Jafari Pouyan E, Abbasi M. Evaluation of the performance of hospital managers in the city of Sari. Hospital J. 2017;17(1):29-45.

9. Krawczyk-Sołtys A. From Healthcare Manager's Competencies To Healthcare Organization's Competences. JManag. 2017(2):31.

10. Mokhtar AM. The Future Hospital: A Business Architecture View. Malays J Med Sci. 2017;24(5):1.

11. Agha Mohammadi S, Jahangiry K, Hajinabi K, Maseoudi Asl I, Dehnavieh R. Forecasting the distribution of hospital bed beds in Iran: Horizon 1414. J health Manag. 2017;71(21):23-37.

12.Herd AM, Adams-Pope BL, Bowers A, Sims B. Finding What Works: Leadership Competencies for the Changing Healthcare Environment. J Leader Edu. 2016;15(4):217-33.

13. Executives ACoH. ACHE Healthcare Executive 2016 Competencies Assessment Tool. 2016.

14. Shafii M, Hosseini SM, Arab M, Asgharizadeh E, Farzianpour F. Performance analysis of hospital managers using fuzzy AHP and fuzzy TOPSIS: Iranian Experience. Glob J Health Sci. 2016;8(2):137-56.

15.Ravaghi H. Hospital managers have not passed the excellent course of management IN: NEWS S: 2016.

16. Mahbanooei B, GholipourA, Abooyee Ardakan M. A competency model for general health managers (case: Iran Medical of Health and Education). Iran J Manag Stud. 2016;9(2):217.

17.Higgins JP, Green S. Cochrane handbook for systematic reviews of interventions: John Wiley \& Sons; 2011.

18. Ghorbani Nia R, Shirkhani H, Vali L. Factors Affecting the Future Studies of Educational Hospitals of Kerman University of Medical Sciences. J Health Res. 2018;3(4):323-38.

19.Kermani B, Darvish H, Sarlak Ma, Kolivand P. Developing Competence Modeling of Hospital Managers. J Health Prom Manag. 2017;6(4):58-65.

20.Van Tuong P, Thanh ND. A Leadership and Managerial Competency Framework for Public Hospital Managers in Vietnam. AIMS Public Health. 2017;4(4):418.

21.Patnaik S, Gupta SK, Kant S, Pillay R. Analyzing Competencies of health care leaders: way forward for next generation. Int J Res Found Hosp Healthcare Adm. 2017;5(1):47-53.

22.Barati O, Sadeghi A, Khamarnia M, Siavashi E, Oskrochi G. a Quantative study to identify skills and competency required for hospital managers. J Electron Phisic. 2016;8(6):2458-65.

23. Federation TIH. Leadership Competencies for Healthcare Services Managers. 2015.

24. Yphantides N, Escoboza S, Macchione N. Leadership in public health: new competencies for the future. Front Public Health. 2015;3:24.

25.Love DB, AFemi Ayadi M. Redefinding the core competencies of future health care executives under healthcare reform. Adm Issues J. 2015;5(2):3-16.

26. Sinz H, Kostenzer J, Walch S. Future health care Managers and the 
need for an international and interprofessional learning ExperienceThe case of a summer school on Cross-Border health care. Int J Teach Edu. 2015;111(2):30-48.

27. Hayati H, Dadgar E, Jannati A. The study of various models of hospital manager's competency. Health Inf Manage. 2015;12(5):680.

28. Khadka DK, Gurung M, Chaulagain N. Managerial competencies-A survey of hospital managers' working in Kathmandu valley, Nepal. J Hosp Adm. 2013;3(1):62.

29.Daire J, Gilson L, Cleary S. Developing leadership and management competencies in low and middle-income country health systems: a review of the literature. Cape Town: Resilient and Responsive Health Systems (RESYST). 2014.

30. Casilas A, Paroz S, Green AR, Wolf H, Weber O, Fucherre F, et al. Cultural competency of health-care providers in a Swiss University Hospital: self-assessed cross-cultural skillfulness in a cross-sectional study. BMC Med Educ. 2014;14(19):1-8.

31.Ranjbar M, Khaef Elahi A, Danaee Fard H, Fani A. Measurig competency model for managers in the health sector (structural equation modeling approach). $\mathrm{J}$ Mazandaran $\mathrm{U}$ Med $\mathrm{S}$. 2014;23(109):104-13.

32. Umbetzhanova A, Derbbissalina G, Koikov V, karakbayeva L. Review of Hospital managers competencies in Astana. CBU International Conference on Innovation, Technology Transfer and Education; Prague, Czech Republic2014. p. 293-8.

33. Kiaei M, Salari M, Moradi R. Assessment of effective management skills in managers of teaching hospitals in Qazvin university of medical sciences (2013). J Qazvin Univ Med Sci. 2014;18(5):51-6.

34.Farzianpour F, Zarei E, Pouragha B, Parvin AB, Mohammadzadeh Jamalian M. Managers' Development Needs Assessment: Perspective of Middle Managers of Public Hospitals of Tehran. J Hospital. 2013;2(49):30-6.

35. Schoenmaker SG, Berkenbosch L, Ahern S, Busari JO. Victorian junior doctors' perception of their competency and training needs in healthcare management. Aust Health Rev. 2013;37(4):412-7.

36. Rinkoo A, Tauqeer nabi R, Surendra Pratap S, Leela Masih H. Scenario-specific, statistically sound, Problem-driven Approach to Data Analysis - A Robust Tool for Future Health Managers. J Int Med Sci Acad. 2013:235-8

37. Yousefinezhadi T, Tabibi S, Riahi L. Evaluation of managers based on 360-degree feedback in teaching hospitals of Tehran University of Medical Sciences. J Rafsanjan Uni Med Sci. 2013;12(9):709-18.

38.Lin LM, Chen HJ, Chen PF, Tennyson RD. Critical Managerial Activity and Competency of Healthcare Management: A Study of Eighteen Hospitals. Int J Asian Bus Inform Manag. 2012;3(1):11-20.

39. Ehsani A, Moshabbaki A, Hadizadeh M. Identification of key capabilities for effective implementation of knowledge management in hospitals with structural equation modeling approach. J Health Adm. 2012;15(49):58-68.

40. Ganda GHP, Kawa S. Management of the Free Health Care Initiative in Sierra Leone: Does the Health Workforce have the Right Managerial Competencies? Thesis for Masters degree in Business Administration. Spring 2012.

41. Tabibi SJ, Fathi M, Riyahi L, Yousefinejad T. relationship between managers competencies and efficiency in educational hospital in tehran university of maedical science. J Teb va Tazkieh. 2010;77:1725.

42. Supic ZT, Bjegovic V, Marinkovic J, Milicevic MS, Vasic V. Hospital management training and improvement in managerial skills: Serbian experience. J Health Policy. 2010;96(1):80-9.

43. Pillay R. The skills gap in hospital management: a comparative analysis of hospital managers in the public and private sectors in South Africa. J Health Manag. 2010;12(1):1-18.

44.Fang $\mathrm{CH}$, Chang ST, Chen GL. Competency development among Taiwanese healthcare middle manager: A test of the AHP approach. Afr J Bus Manage. 2010;4(13):2845.

45. Kebede S, Abebe Y, Wolde M, Bekele B, Mantopoulos J, Bradley EH. Educating leaders in hospital management: a new model in SubSaharan Africa. Int J Qual Health Care. 2009;22(1):39-43.

46. Lockhart W, Backman A, editors. Health care management competencies: identifying the GAPs. Healthcare Management Forum; 2009: Elsevier.

47.El-Jardali F, Tchaghchagian V, Jamal D. Assessment of human resources management practices in Lebanese hospitals. Hum Resour Health. 2009;7(1):84.

48. Stefl ME. Common competencies for all healthcare managers: the healthcare leadership Alliance model.

49.Pillay R. Physician perceptions of managed care strategies, and impact of these on their clinical performance, in the South African private health sector. Health Serv Manage Res. 2008;21(1):1-13.

50.Pillay R. Defining Competencies For Hospital Management: A comparative analysis of the public and private sectors. Leadersh Health Serv. 2008;21(2):99-110.

51.Vincent JL, Creteur J. The hospital of tomorrow in 10 points. Crit Care. 2017;21(1):93.

52. Behrens LL, McGhan G, Abbott KM, Fick DM, Kolanowski AM, Liu Y, et al. Mapping Core Concepts of Person-Centered Care in LongTerm Services and Supports. J Gerontol Nurs. 2019;45(2):6.

53. Ghorbani Nia R, Shirkhani H, Leila V. Factors Affecting the Future Studies of Educational Hospitals of Kerman University of Medical Sciences. J Health Res. 2017;3(4):323-338

54.Hu M, Monica C, Horng J, Teng C. Developing A model for an innovative culinary competency curriculum and examining its effects on students' performance. J Creat Behav. 2016.

55.Gaviria-Marin MMJ, Baier-Fuentes H. Knowledge management: A global examination based on bibliometric analysis. Technol Forecast Soc Change. 2019;1(140):26.

56. Altbach PG, Reisberg L, Rumbley LE. Trends in global higher education: Tracking an academic revolution. Brill Sense. 2019.

57. Rocklage M, Fazio R. Attitude accessibility as a function of emotionality. Pers Soc Psychol Bull. 2018;4(44):12.

58. Amini S, Dehnavieh R. Future Wheel: Unclear, But Applicable and Succeeding in Promoting Community Health. Health Inf Manage J. 2015;12(3):273-5.

59. Ghanem M, Schnoor J, Heyde C, Kuwatch S, Bohn M, Josten C. Management strategies in hospital:scenario planning. GMS Interdiscip Plast Reconstr Surg DGPW. 2015;4:1-7.

60. Ross Baker G. Identifying and Assessing competencies: A Strategy to improve Healthcere Leadership. Health care. 2014;4(1). 